\title{
Self-confidence, commitment and goal-setting in Czech athletes at different performance levels
}

\author{
Michal Vičar* \\ Faculty of Sports Studies, Masaryk University, Brno, Czech Republic
}

\begin{abstract}
Background: Numerous studies rank self-confidence, commitment and goal-setting among the foundation mental skills in athletes, conditioning the development of elite performance and also contributing to achieving first rate results during competition. Their quality is, therefore, essential for top performance. Objective: The goal of this study is a comparison of self-confidence, commitment and goal-setting in Czech athletes performing at different performance levels. The secondary aim is to compare the values gathered in Canadian and Czech populations. Methods: The Czech version of the OMSAT-3* questionnaire was distributed to 241 athletes at regional $(n=63)$, national $(n=115)$ and international levels $(n=63)$. Only the part of the questionnaire focusing on the selected mental skills ( 3 out of 12 scales) was used. Subsequently, the data were compared with the Canadian population $(N=335)$ used for standardization of the original questionnaire. Results: The values among Czech athletes manifest that the differences in mean values is statistically significant in all mental skills (goal-setting $p=.03$, self-confidence $p<.01$, commitment $p=.03$ ). Differences among groups dependent on the current level of performance are significantly higher in goal-setting ( $p=.05, d=0.46)$ self-confidence ( $p<.01, d=0.63)$, and commitment $(p<.01, d=0.55)$ of athletes at international level compared to regional level and in self-confidence $(p<.01, d=0.46)$ and commitment $(p<.01, d=0.49)$ of athletes at national level compared to regional level. There is no significant difference among national and international athletes. Canadian respondents show statistically significant higher mean values than Czech athletes in all selected mental skills. Conclusions: The level of self-confidence, goal-setting, and commitment in Czech athletes differs according to performance level. Czech athletes show lower values in all mental skills considered compared to the Canadian sample.
\end{abstract}

Keywords: mental skill, OMSAT-3*, socio-cultural differences, top performance, talent development

\section{Introduction}

Numerous studies (e.g., Horn, 2002; Weinberg \& Gould, 2011) identify and analyse psychological characteristics possessed by elite athletes. They compare elite athletes with the less successful ones with the intention of revealing the reasons behind the excellence of some athletes. Among the most described differential psychological attributes are the quality of selfconfidence, goal-setting and commitment, classified as mental skills by Durand-Bush and Salmela (2001).

Mental skills are characteristics of athletes, determining their sport performance to a considerable extent. According to Lesyk (1998), these mental skills are trainable, and their improvement leads to better performance in sport. Durand-Bush, Salmela,

\footnotetext{
* Address for correspondence: Michal Vičar, Department of Social Sciences and Sports Management, Faculty of Sports Studies, Masaryk University, Kamenice 5, 62500 Brno, Czech Republic. E-mail: vicar@fsps.muni.cz
}

and Green-Demers (2001) categorize self-confidence, goal-setting and commitment among the so-called foundation mental skills. They consider these skills as the basis for a consistent sport performance at the elite level. Concurrently, these are recognised as building blocks for development of the remaining mental skills (Orlick, 1992). Durrand-Bush and Salmela (2001) assert that their development determines, to a considerable extent, the development of sport talent in general. This approach is shared by Vičar, Protič, and Válková (2014).

The importance of self-confidence in reaching elite performance in sport is documented by several studies (e.g., Porter, 2003). Self-confidence means being aware of an individual's qualities and abilities accompanied by a faith in successful future performances (Hartl \& Hartlová, 2000). Orlick (1992) claims that several beliefs play a role in reaching the highest levels of personal excellence, namely the belief in our own potential, belief in our goal, belief that this goal is important and meaningful, and belief that we are able to reach this 
goal. High expectations are characteristic of self-confidence which acts as a significant factor differentiating highly successful athletes from less successful ones (Kruger, Potgieter, Malan, \& Steyn, 2010). A fulfilled assumption - the so called self-fulfilling prophecy, is a typical phenomenon where self-confidence is projected into a real situation. In other words, if an individual anticipates certain results, the anticipation will help fulfil the expectations. Contrarily, discrepancy with the expectations arouse frustration in the athlete. This is comprised of anger, aggression and disappointment (Slepička, Hošek, \& Hátlová, 2006). Self-confidence instigates positive emotions (Hays, Maynard, Thomas, \& Bawden 2007), improves concentration (Weinberg $\&$ Gould, 2011), facilitates goal-setting (Hays et al., 2007), has a positive effect on the effort devoted (Harwood, Cumming, \& Fletcher, 2004) and maintains the intensity of the mental processes depending on the development in the game.

Goal-setting is an equally essential skill in sport performance. Goals signify set results the individual aspires to achieve. A positive impact of setting short-term and long-term goals as motivational factors and their influence on performance were validated by a number of studies (e.g., Holgado, Navas \& López-Núñez, 2010; Locke \& Latham, 2002). The ability to set realistic and yet challenging goals is considered a fundamental mental skill associated with first-rate performances according to MacNamara, Button, and Collins (2010). Based on extensive research of the literature dealing with goal-setting, Locke and Latham (1990) concluded that goal-setting appears to be beneficial to a majority of athletes across a wide range of tasks and environments. The ability to set realistic and yet challenging goals is considered a fundamental mental skill associated with first-rate performances according to MacNamara et al. (2010). Goal-setting helps athletes to focus their attention, retain their commitment and persistence, raise self-confidence and manage fear (Burton, 1993).

Motivation is the basic precondition for the third mental skill - commitment. However physically talented the athlete might be, it is apparent that without immense dedication they cannot reach elite performances. The given activity must become the central point of the athlete's life. Orlick (1992) thus perceives the level of the athlete's commitment as the key ingredient for success.

The importance of commitment in sport performance development is underlined by studies of Ericsson (2000) and his team (Ericsson, Krampe, \& TeschRömer, 1993). The authors focus on the role of training and practise in the development of potentially talented individuals. In their research of elite athletes, musicians, artists etc., Ericsson et al. (1993) estimate that experts spend 10 years or 10,000 hours of conscious efforts in acquiring experience, termed deliberate practice, before they reach exceptional performance. This assumption is currently known as the " 10 -year rule", where ten years of practice are necessary for reaching the maximum level of performance. This claim is supported, for example, by the study and work of Baker (2003), Helsen, Starkes, and Hodges (1998), or Starkes, Deakin, Allard, Hodges, and Hayes (1996). The researchers drew a conclusion that individuals reaching elite performance not only spend more time on training but also dedicate more time to practising activities considered suitable for development of fundamental skills and abilities necessary for achieving an elite level. Ericsson's theory is subsequently reflected in the most influential modern theories of talent development in various forms (e.g., Bailey \& Morley, 2006).

Although, regarding various research exists documenting different levels of quality of skills in elite and amateur athletes (see below), this study aims to expand the results by adding the population of Czech athletes. The diagnostics are acquired using the OMSAT-3* questionnaire (Durand-Bush et al., 2001; adapted by Vičar, 2017), aimed at assessing of athletes' mental skills. Also, during its standardisation into Czech, significant differences in sociocultural perception and interpretation of several psychological characteristics were identified. Consequently, the research goal of this study is identification of differences between fundamental mental skills (self-confidence, commitment and goal-setting) in Czech athletes competing at different performance levels (regional, national, international). The secondary aim is a comparison of the fundamental mental skills values between the Canadian and Czech samples.

\section{Methods}

\section{Participants}

The research sample includes 241 athletes competing at different performance levels (regional level, national level, international level). Respondents were recruited from 22 sports; primarily football $(n=78)$, handball $(n=34)$, basketball $(n=42)$, volleyball $(n=23)$ and judo $(n=11)$. The selection of the research sample was carried out by purposive sampling in combination with the snowball technique sampling. The lower age limit was set at 15 years - based on the recommendations of the author of the Czech version. The basic characteristics of the research sample are summarised in Table 1. Informed consent was signed by all the athletes. Athletes under 18 were represented with their legal representative. The research was approved by the ethical committee. 
Table 1

Basic characteristics of the research sample

\begin{tabular}{|c|c|c|c|c|c|c|}
\hline \multirow[b]{2}{*}{ Performance level } & \multicolumn{3}{|c|}{ Gender } & \multicolumn{3}{|c|}{ Age (years) } \\
\hline & Men & Women & Total & $M$ & $S D$ & Range \\
\hline Regional & 40 & 23 & 63 & 20.94 & 4.76 & $15-32$ \\
\hline National & 80 & 35 & 115 & 18.76 & 3.82 & $15-32$ \\
\hline International & 37 & 26 & 63 & 19.70 & 3.87 & $15-32$ \\
\hline Total & 157 & 84 & 241 & 19.57 & 4.18 & $15-32$ \\
\hline
\end{tabular}

\section{Research tool}

A part of the Ottawa Mental Skill Assessment Tool (OMSAT-3*) questionnaire (Durand-Bush et al., 2001) was used as the research tool. OMSAT-3* is a diagnostic tool used extensively all around the world to assess the quality of mental skills of both professional and amateur athletes (e.g., Guelmami, Hamrouni, \& Agrébi, 2014). It is its 3 rd modified version by the authors.

The original OMSAT- $3 *$ is composed of forty-eight questions in total, focusing on twelve psychological characteristics divided into three groups - foundation skills (self-confidence, commitment and goal-setting), psychosomatic skills (stress control, fear control, relaxation and activation) and cognitive skills (focusing, refocusing, imagery, mental practice and competition planning). The Czech version adapted by Vičar (2017) confirmed psychometric characteristics only in 7 out of 12 scales (goal-setting, self-confidence, commitment, activation, focusing, competition planning and mental practice). The remaining dimensions (relaxation, fear control, stress reaction, imagery and refocusing) display insufficient internal consistency. The items on the scales (12 in total) assessing fundamental skills (goal-setting, self-confidence, commitment), however, proved sufficiently valid and reliable in the Czech version. Only these three scales are used in this research.

The questionnaire further comprises questions referring to education and the highest as well as the current level of involvement in sport, gender, age, country of origin and sport discipline.

The answers were recorded on a 7-point Likert scale ranging from "strongly disagree" to "strongly agree" with the median value being "don't agree / don't disagree". The authors of the original version of the questionnaire also observe that the questionnaire can be applied to any sport. They also claim that testing can start from the age of 9. However, the author of the Czech version, Vičar (2017), argues that Czech respondents fully comprehended the questions in the questionnaire only from the period of young adolescence, i.e., at the age of 15 .
Operational definitions of selected mental skills are listed below as described in the original study of Durrand-Bush et al. (2001).

Goal-setting is the process by which individuals establish objectives or goals that provide them with a direction and the motivation to achieve an end result (Burton, 1993; Locke \& Latham, 1990).

Self-confidence refers to a feeling or belief in one's own abilities and personal goals (Orlick, 1992; Vealey, 1986).

Commitment reflects one's intensity and dedication toward achieving desired goals (Orlick, 1992).

The research sample of the original Canadian study (Durrand-Bush et al., 2001) was comprised of 335 athletes from 35 different sports in total. The age of athletes varied between 9-42 years, while the average age is 19.6. The sample was composed of 175 men and 160 women. The researchers differentiated only two groups of respondents: international athletes - elite athletes competing at international level $(n=147)$ and competitive athletes - competing at a regional or national level $(n=188)$. In order to compare the results with the Canadian research sample, Czech respondents were merged from the regional and national level into one competitive group (178 respondents in total).

Data were collected by a psychologist trained in the method. He administrated the OMSAT- $3 *$ after the training or in the athlete's free time. On average, it took 10 minutes to fill in the paper questionnaire. Respondents were motivated by the administrator to gain knowledge about their mental skill level.

\section{Statistical analysis}

SPSS statistical software (Version 19 for Windows; IBM, Armonk, NY, USA) was used for data calculation. The significance level was set at 0.05 for all statistical tests. For statistical analysis of data, the Levene test for calculating homogeneity of variances was used. Subsequently, ANOVA method was used and rather conservative post hoc Scheffé's method for comparison of means was applied. Comparison of the values acquired from the Canadian and the Czech sample was 
based on the calculation of means, standard deviations and standard errors using $t$-test.

\section{Results}

The values stated (Table 2) manifest ANOVA procedure and mean values. The results indicate that differences in means in all mental skill among groups are statistically significant at .05 level. The biggest difference was documented in commitment ( 0.73 points), the smallest fluctuation was in goal-setting ( 0.43 points).

The results of the post hoc test (Table 3) show that the differences related to the current level of performance are statistically significant only in certain groups, but all of them with medium effect size determined by Cohen's $d$. It includes self-confidence ( 0.51 points, $d=0.46)$ and commitment ( 0.65 points, $d=0.49$ ) among the regional and national level athletes, and self-confidence ( 0.60 points, $d=0.63)$, commitment ( 0.73 points, $d=0.55)$ and goal-setting $(0.43$, $d=0.46)$ in the regional and international level. On the other hand, there is no difference in mental skills among national and international athletes.
Table 4 clearly shows that Canadian respondents stated statistically significant higher values than Czech athletes - both at a competitive level and at an international level. All of these differences have medium size effect with the exception of self-confidence among elite athletes ( $d=0.86$ - large effect size). Smallest difference is in commitment among competitive athletes $(d=0.28-$ medium effect size $)$

\section{Discussion}

The results of the sample show that selected mental skills differ according to performance level, but there is no difference among national and international athletes. The significant differences among particular group levels are in self-confidence and commitment in regional and national level athletes, and goal-setting, self-confidence and commitment at the regional and international level. Significant differences were also identified in the mental skills values stated by the Canadian and Czech athletes. The results correspond with most of the former conclusions.

Table 2

Results of ANOVA and values of mental skills divided according to athletes' performance levels

\begin{tabular}{|c|c|c|c|c|c|c|c|c|}
\hline \multirow[b]{3}{*}{ Mental skill } & & & \multicolumn{6}{|c|}{ Performance level } \\
\hline & \multicolumn{2}{|c|}{ ANOVA } & \multicolumn{2}{|c|}{ Regional } & \multicolumn{2}{|c|}{ National } & \multicolumn{2}{|c|}{ International } \\
\hline & $F$ & $p$ & $M$ & $S D$ & $M$ & $S D$ & $M$ & $S D$ \\
\hline Goal-setting & 3.70 & .03 & 4.91 & 1.00 & 5.25 & 0.99 & 5.34 & 0.87 \\
\hline Self-confidence & 6.93 & $<.01$ & 4.50 & 0.91 & 5.03 & 0.91 & 5.10 & 1.00 \\
\hline Commitment & 6.05 & .03 & 4.54 & 1.31 & 5.19 & 1.36 & 5.27 & 1.34 \\
\hline
\end{tabular}

Table 3

Results of post hoc tests following ANOVA tests on mental skills

\begin{tabular}{|c|c|c|c|c|c|c|c|c|}
\hline \multirow[b]{2}{*}{ Mental skill } & \multicolumn{4}{|c|}{ National level } & \multicolumn{4}{|c|}{ International level } \\
\hline & $M$ diff. & $S E$ & $p$ & $d$ & $M$ diff. & $S E$ & $p$ & $d$ \\
\hline \multicolumn{9}{|l|}{ Goal-setting } \\
\hline Regional level & 0.35 & 0.15 & .07 & 0.34 & 0.43 & 0.17 & .05 & 0.46 \\
\hline National level & & & & & 0.08 & 0.15 & .87 & 0.10 \\
\hline \multicolumn{9}{|l|}{ Self-confidence } \\
\hline Regional level & 0.51 & 0.15 & $<.01$ & 0.46 & 0.60 & 0.17 & $<.01$ & 0.63 \\
\hline National level & & & & & 0.09 & 0.15 & .83 & 0.07 \\
\hline \multicolumn{9}{|l|}{ Commitment } \\
\hline Regional level & 0.65 & 0.21 & $<.01$ & 0.49 & 0.73 & 0.24 & $<.01$ & 0.55 \\
\hline National level & & & & & 0.08 & 0.21 & .92 & 0.09 \\
\hline
\end{tabular}

Note. $\quad M$ diff. $=$ difference in means; $d=$ Cohen's $d$. 
Table 4

Comparison of selected mental skills of the Canadian and Czech populations

\begin{tabular}{|c|c|c|c|c|c|c|c|}
\hline & \multicolumn{2}{|c|}{ Canadian } & \multicolumn{2}{|c|}{ Czech } & \multirow[b]{2}{*}{$M$ diff. } & \multirow[b]{2}{*}{$n$} & \multirow[b]{2}{*}{$d$} \\
\hline & $M$ & $S D$ & $M$ & $S D$ & & & \\
\hline \multicolumn{8}{|c|}{ International athletes } \\
\hline Goal-setting & 5.81 & 0.80 & 5.34 & 0.87 & 0.47 & $<.01$ & 0.56 \\
\hline Self-confidence & 5.88 & 0.69 & 5.14 & 1.00 & 0.74 & $<.01$ & 0.86 \\
\hline Commitment & 5.96 & 0.77 & 5.27 & 1.34 & 0.49 & $<.01$ & 0.63 \\
\hline \multicolumn{8}{|c|}{ Competitive athletes } \\
\hline Goal-setting & 5.60 & 0.90 & 5.12 & .99 & 0.48 & $<.01$ & 0.51 \\
\hline Self-confidence & 5.55 & 0.93 & 4.85 & 0.94 & 0.70 & $<.01$ & 0.75 \\
\hline Commitment & 5.30 & 1.15 & 4.94 & 1.37 & 0.36 & $<.01$ & 0.28 \\
\hline
\end{tabular}

Note. $\quad M$ diff. = difference in means; $d=$ Cohen's $d$.

For example, in a traditional research, Mahoney and Avener (1977) assessed the importance of various psychological attributes for performance of athletes performing in gymnastics, wrestling, tennis, racquetball and diving at various competition levels using a simple non-standardized questionnaire. The conclusion of the research shows consistent results across the analysed samples: the most successful athletes were more self-confident and less doubtful about their abilities and skills. Thomas and Over (1994) and Thomas, Schlinker, and Over (1996) validated this conclusion also in golf and bowling. The authors further observe a higher level of dedication in athletes who attain higher performance. These findings correspond with the result of this study.

Similar to the findings of this research, the difference in the level of self-confidence and commitment was observed also by Mahoney, Gabriel, and Perkins (1987) who used a 45-item questionnaire called "Psychological Skills Inventory for Sports - PSIS" for measurement. Elite athletes from various sport disciplines showed higher self-confidence and overall higher level of motivation than their amateur colleagues. Analogous conclusions were drawn by other studies using PSIS for example in rodeo (Meyers, LeUnes, \& Bourgeois, 1996) or equestrianism (Meyers, Bourgeois, LeUnes, $\&$ Murray, 1999). These findings consistently support our results regardless using different test method.

The above-mentioned studies, in accordance with the present study, did not take into consideration the process causality and the role of mental skills in sport performance. Precisely the wider connections between these psychological attributes and elite performance were researched by qualitative studies of Olympic and other elite athletes. The research by MacNamara et al. (2010), for example, included interviews with world class athletes and their parents. The respondents emphasised the role of mental skills and characteristics in reaching elite performance. They also accentuated dedication to the given sport, self-confidence and the vision of the path to success.

The vision of the path to success is related to the third mental skill - goal-setting, where differences among regional and international level of performance were discovered in this study. In accordance with these findings, a higher level of this skill in elite athletes was identified, for example, by Gould, Diffenbach, and Moffett (2002). Through interviews, they ascertained that Olympic winners have a developed sense of setting and accomplishing goals.

The findings of this study using the Czech version of OMSAT-3* about goal-setting correspond with results using different world-wide distributed questionnaire "The Test of Performance Strategies - TOPS" (Thomas, Murphy, \& Hardy, 1999). As in our findings, the results showed that, when compared to the athletes at lower performance levels, the athletes performing at an international level (both men and women) stated more often the utilisation of skills in the area of goalsetting, among others.

Based on the findings described above, it can be stated that a majority of conclusions describing the variations in mental skills in the population of Czech athletes at different performance levels is consistent with earlier research. However, this research did not identify a difference in mental skills in athletes performing at international or national levels. This will be explained subsequently.

Firstly, the sample of athletes performing at an international level is relatively small. It is thus not certain how purposively specific the research sample is in this respect. Secondly, it is questionable, whether 
self-reported high quality of basic mental skills is encouraging sports performance. For example, commitment and goal-setting is often mentioned by researchers in context of intrinsic motivation. A threat of excessive motivation is traditionally connected with overpressure and overload (Hermans, 1970). Also, self-confidence is related to the quality of self-esteem. In this context, we talk about optimal self-esteem. Baumeister, Campbell, Krueger, and Vohs (2003) assert that adequate self-esteem is important for the knowledge of one's limits and for identifying fields open for future improvement. Kernis (2003) adds that optimum self-esteem is not congruent with high self-esteem. He states that:

High self-esteem can be fragile or secure depending upon the extent to which it is defensive or genuine, contingent or true, unstable or stable, and discrepant or congruent with implicit (nonconscious) feelings of self-worth. Optimal self-esteem is characterized by qualities associated with genuine, true, stable, and congruent (with implicit self-esteem) high self-esteem. (Kernis, 2003, p. 1)

It is therefore possible to assume that excessive levels of mental skills can be counter-productive in elite sport.

Finally, the original Canadian study (Durrand-Bush et al., 2001) does not distinguish between athletes performing at national level and regional level - national level is merged into one "competitive group" with a group performing at regional level. Similar differences could, therefore, have been identified also in the original research.

It is worth mentioning the comparison of results with the earlier assessments using the OMSAT-3* questionnaire. The original Canadian research sample showed substantially higher values in mental skills in comparison with Czech athletes. The differences can be rationalised by several reasons: First of all, Canadian athletes have been able to attain superior mental skills. Considering the fact that Lesyk (1998) regards mental skills as practicable, which means dependent on environment, a different approach to training of overseas athletes might, therefore, lead to higher mental skills quality. Vealey (2007), for example, asserts that mental practice is becoming an increasingly more common part of an athlete's preparation on the North American continent. Hřebičková (2013), on the other hand, observes that despite athletes and coaches in the Czech Republic often accentuating the importance of improving athlete's psyche, mental preparation itself tends to be associated only with elite sport at national or international levels.

Secondly, since the athletes are assessing themselves in the questionnaire, it is plausible that the difference has a sociocultural cause - Czech people may be humbler in reflecting on their mental skills. This fact is highlighted by a number of studies dealing with cross-cultural comparison of respondents' answers to questions in selfassessment questionnaires. Sedikides, Gaertner, and Toguchi (2003) and Sedikides, Gaertner, and Vevea (2005), for example, describe how Americans, Canadians and Western Europeans and East Asians assess themselves in various attributes. East Asians describe themselves more negatively than North Americans and Western Europeans. These differences tend to be especially large when people evaluate their agentic qualities (e.g., "How capable are you?"). It can be presumed that similar differences could be found among North Americans and Eastern Europeans, even in sport setting, explaining the differences in Czech and Canadian athletes. Moreover, particularly the differences in selfesteem in different countries were dealt with by Schmitt and Allik (2005). Using the Rosenberg Self-Esteem Scale assessing 16,998 respondents including Canada, USA, the Czech Republic and Slovakia, they concluded that levels of self-esteem differ from country to country. Compared to Czechs and Slovaks, North Americans reported higher levels in both self-esteem and self-love. It is worth mentioning that the greatest difference between the Canadian and Czech populations is on the self-confidence scale. A higher degree of self-confidence in North Americans is therefore often mentioned unofficially by Czech athletes as a noteworthy cultural difference when comparing themselves with their competitors. These common statements need, however, to be supported with further research.

The results of this study may be compared to results acquired from OMSAT-3* adaptations in different languages. The mean values of fundamental mental skills in Arabic-speaking athletes (Noômen, Mohamed, Nasri, \& Brahim, 2015; sample of 526 Tunisian athletes on international level and competitive athletes aged between 16 and 19 years) are even lower than in the Czech population. The same applies to goal-setting (international athletes -0.72 , competitive athletes -0.59 ), self-confidence (international athletes -0.33 , competitive athletes -0.30 ), and commitment (international athletes -0.21 , competitive athletes -0.18 ). It must be noted however that the Tunisian research sample is considerably younger compared to the sample of this study. The data acquired from the Romanian adaptation of the OMSAT-3* (Craciun, Dobosi, \& Rusu, 2009) based on the 99 respondents performing at an international level can be only compared within athletes at international level. Mean values are lower when compared to the Czech athletes performing at an international level in goal-setting $(-0.06)$ and higher in self-confidence $(+0.07)$ and commitment $(+0.44)$ 
Generally saying, international comparisons and variations identified only highlight the impact of the sociocultural environment on the quality of mental skills. The results thus substantiate the necessity of creating new norms for language adaptations of the OMSAT-3* questionnaire. Also, no discovered differences among international and national athletes in our study open space for future research. Another interesting question for follow-up studies is, whether the level of fundamental skills depends on the sports discipline, e.g., if there is a difference between team and individual sports.

\section{Conclusion}

This study assessed the quality of mental skills - selfconfidence, goal-setting and commitment, ranked among foundation skills, using the Czech version of the OMSAT-3* questionnaire. Their level in Czech athletes statistically significantly differ in various performance levels (region, national, international). There is no difference found among international and national athletes in any of the skills. We can find medium sized differences in self-confidence and commitment at the regional (lower) and national level athletes (higher), and goal-setting, self-confidence and commitment at the regional (lower) and international level (higher). On the other hand, no differences among international and national athletes was discovered.

Compared to the original research of the Canadian population carried out by the authors of the OMSAT$3 *$, Czech athletes show lower values in all mental skills considered. Yet the causality of the differences remains unclear. It is not certain whether the mental skills develop as a consequence of top performance or vice versa. The results, however, do support to point out the importance of the development of selfconfidence, goal-setting and commitment for Czech athletes' top performance.

\section{Conflict of interest}

There were no conflicts of interest.

\section{References}

Bailey, R., \& Morley, D. (2006). Towards a model of talent development in physical education. Sport, Education and Society, 11, 211-230.

Baker, J. (2003). Early specialisation in youth sport: A requirement for adult expertise? High Ability Studies, 14, $85-94$.
Baumeister, R. F., Campbell, J. D., Krueger, J. I., \& Vohs, K. D. (2003). Does high self-esteem cause better performance, interpersonal success, happiness, or healthier lifestyles? Psychological Science in the Public Interest, 4, 1-44.

Burton, D. (1993). Goal setting in sport. In R. N. Singer, M. Murphey, \& L. K. Tennant (Eds.), Handbook of research on sport psychology (pp. 511-527). New York, NY: Macmillan Publishers.

Craciun, M., Dobosi, S., \& Rusu, F. (2009). A confirmatory factor analysis of the Ottawa Mental Skill Assessment Tool (OMSAT-3*) - Romanian version. European Journal of Physical \& Health Education, 2, 87-96.

Durand-Bush, N., \& Salmela, J. H. (2001). The development of talent in sport. Sport Psychologist, 20, 269-284.

Durand-Bush, N., Salmela, J. H., \& Green-Demers, I. (2001). The Ottawa Mental Skills Assessment Tool (OMSAT-3). Sport Psychologist, 15, 1-19.

Ericsson, K. A. (2000). How experts attain and maintain superior performance: Implications for the enhancement of skilled performance in older individuals. Journal of Aging and Physical Activity, 8, 366-372.

Ericsson, K. A., Krampe, R. T., \& Tesch-Römer, C. (1993). The role of deliberate practice in acquisition of expert performance. Psychological Review, 100, 363-406.

Gould, D., Diffenbach, K., \& Moffett, A. (2002). Psychological characteristics and their development in Olympic champions. Journal of Applied Sport Psychology, 14, 172-204.

Guelmami, N., Hamrouni, S., \& Agrébi, B. (2014). Psychological profiles of talented male youth athletes in team sports games. Journal of Physical Education and Sports Management, 5, 5-10.

Hartl, P., \& Hartlová, H. (2000). Psychologický slovník [Psychological dictionary]. Prague, Czech Republic: Portál.

Harwood, C. G., Cumming, J., \& Fletcher, D. (2004). Motivational profiles and psychological skills use within elite youth sport. Journal of Applied Sport Psychology, 16, 318-332.

Hays, K., Maynard, I., Thomas, O., \& Bawden, M. (2007). Sources and types of confidence identified by world class sport performers. Journal of Applied Sport Psychology, 19, 434-456.

Helsen, W. F., Starkes, J. L., \& Hodges, N. J. (1998). Team sports and the theory of deliberate practice. Journal of Sport and Exercise Psychology, 20, 12-34.

Hermans, H. J. (1970). A questionnaire measure of achievement motivation. Journal of Applied Psychology, 54, 353-363.

Holgado, F. P., Navas, L., \& López-Núñez, M. (2010). Goal orientations in sport: A causal model. European Journal of Education and Psychology, 3, 19-32.

Horn, T. (Ed.). (2002). Advances in sport psychology (2nd ed.). Champaign, IL: Human Kinetics.

Hřebíčková, H. (2013). Mentální trénink v př́pravě alpských lyžařu junioru [Mental training in the preparation of junior Alpine skiers] (Unpublished doctoral dissertation). Palacký University Olomouc, Olomouc, Czech Republic.

Kernis, M. H. (2003). Toward a conceptualization of optimal self-esteem. Psychological Inquiry, 14, 1-26.

Kruger, P., Potgieter, J., Malan, D., \& Steyn, F. (2010). Prior experience, cognitive perceptions and psychological skills 
of senior South African rugby players. South African Journal for Research in Sport, Physical Education \& Recreation, 32, 69-84.

Lesyk, J. J. (1998). The nine mental skills of successful athletes: A holistic model for assessing and teaching mental skills to athletes. Workshop presented at the Annual Conference of the Association for the Advancement of Applied Sport Psychology (AAASP). Hyannis, MA, USA.

Locke, E. A., \& Latham, G. P. (1990). A theory of goal setting \& task performance. Englewood Cliffs, NJ: Prentice Hall.

Locke, E. A., \& Latham, G. P. (2002). Building a practically useful theory of goal setting and task motivation: A 35-year odyssey. American Psychologist, 57, 705-717.

MacNamara, A., Button, A., \& Collins, D. (2010). The role of psychological characteristics in facilitating the pathway to elite performance. Part 1: Identifying mental skills and behaviours. Sport Psychologist, 24, 52-73.

Mahoney, M. J., \& Avener, M. (1977). Psychology of the elite athlete: An exploratory study. Cognitive Therapy and Research, 1, 135-142.

Mahoney, M. J., Gabriel, T. J., \& Perkins, T. S. (1987). Psychological skills and exceptional athletic performance. Sport Psychologist, 1, 181-199.

Meyers, M. C., Bourgeois, A. E., LeUnes, A., \& Murray, N. G. (1999). Mood and psychological skills of elite and subelite equestrian athletes. Journal of Sport Behaviour, 22, 399-409.

Meyers, M. C., LeUnes, A., \& Bourgeois, A. E. (1996). Psychological skills assessment and athletic performance in collegiate rodeo athletes. Journal of Sport Behaviour, 19, $132-146$.

Noômen, G., Mohamed, J., Nasri, H., \& Brahim, A. (2015). Sensitivity, internal consistency and factorial structure of the Arabic version of OMSAT-3. Advances in Physical Education, 5, 18-25.

Orlick, T. (1992). The psychology of personal excellence. Contemporary Thought on Performance Enhancement, 1, 109-122.

Porter, K. (2003). The mental athlete. Champaign, IL: Human Kinetics.

Schmitt, D. P., \& Allik, J. (2005). Simultaneous administration of the Rosenberg Self-Esteem Scale in 53 nations: Exploring the universal and culture-specific features of global self-esteem. Journal of Personality and Social Psychology, 89, 623-642.
Sedikides, C., Gaertner, L., \& Toguchi, Y. (2003). Pancultural self-enhancement. Journal of Personality and Social Psychology, 84, 60-79.

Sedikides, C., Gaertner, L., \& Vevea, J. L. (2005). Pancultural self-enhancement reloaded: A meta-analytic reply to Heine (2005). Journal of Personality and Social Psychology, 89, 539-551.

Slepička, P., Hošek, V., \& Hátlová, B. (2006). Psychologie sportu [Sport psychology]. Prague, Czech Republic: Karolinum.

Starkes, J. L., Deakin, J. M., Allard, F., Hodges, N. J., \& Hayes, A. (1996). Deliberate practice in sports: What is it anyway. The road to excellence: The acquisition of expert performance in the arts and sciences, sports, and games. Mahwah, NJ: Lawrence Erlbaum Associates.

Thomas, P. R., Murphy, S. M., \& Hardy, L. (1999). Test of Performance Strategies: Development and preliminary validation of a comprehensive measure of athletes' psychological skills. Journal of Sports Sciences, 17, 697-711.

Thomas, P. R., \& Over, R. (1994). Psychological and psychomotor skills associated with performance in golf. Sport Psychologist, 8, 73-86.

Thomas, P. R., Schlinker, P. J., \& Over, R. (1996). Psychological and psychomotor skills. Journal Sports Sciences, 14, 255-268.

Vealey, R. S. (1986). Conceptualization of sport confidence and competitive orientation: Preliminary investigation and instrument development. Journal of Sport Psychology, 8, 221-246.

Vealey, R. S. (2007). Mental skills training in sport. In G. Tenenbaum \& R. Eklund (Eds.), Handbook of sport psychology (3rd ed., pp. 287-309). Chichester, United Kingdom: John Wiley and Sons.

Vičar, M. (2017). Sportovní talent a standardizace Ottawského dotazníku mentálních dovedností ve sportu - OMSAT-3* [Sports talent and standardization of Ottawa Mental Skill Assessment Tool - OSMAT-3] (Unpublished doctoral dissertation). Palacký University Olomouc, Olomouc, Czech Republic.

Vičar, M., Protič, M., \& Válková, H. (2014). Sportovní talent - psychologická perspektiva [Sports talent - psychological perspective]. Olomouc, Czech Republic: Palacký University Olomouc.

Weinberg, R. S., \& Gould, D. (2011). Foundations of sport \& exercise psychology. Champaign, IL: Human Kinetics. 